\title{
EL AGUA COMO CLAVE DEL ECODESARROLlO URBANO: PAISAJE, PATRIMONIO, TERRITORIO Y SOCIEDAD
}

\section{ECO-URBAN DEVELOPMENT THROUGHT WATER: LANDSCAPE, HERITAGE, TERRITORY AND SOCIETY}

\author{
María Francisca Zaragoza Martí \\ Universidad de Alicante. Alicante/España. \\ maria.zaragoza@ua.es \\ https://orcid.org/0000-0003-3912-0395
}

Recibido/Received: 29/09/2020

Modificado/Modified: 02/11/2020

Aceptado/Accepted: 23/11/2020

\section{RESUMEN}

Actualmente, más del cincuenta por ciento de la población mundial vive en las urbes, configuradas éstas como lugar de reunión de una multiculturalidad moderna, innovadora y preocupada con su entorno, que no acepta seguir con el planeamiento urbanístico y de crecimiento de las últimas décadas. Surgen así los movimientos sociales actuales que claman por una nueva planificación urbana y paisajística donde se tengan en cuenta los recursos naturales, cambiando el clásico paradigma de la dominación por otro ecosostenible. En consecuencia, a través de una metodología eminentemente jurídica, se pretende exponer la necesaria relación entre el desarrollo paisajístico y el crecimiento urbano, a través del valor inmaterial que el agua posee en la creación de entornos sociales de calidad. A la vista de los resultados, queda patente el escaso valor de los espacios hidrológicos como configuradores del entorno y su nula inclusión como elementos de ordenación urbana y de calidad de vida en la ciudad.

\section{PALABRAS CLAVE}

cambio de paradigma, sostenibilidad, ciudad, derecho humano.

\section{SUMARIO}

1. Introducción. 2. El agua como clave de desarrollo sostenible. 2.1 Paisaje y Patrimonio: la fluviofelicidad como patrimonio inmaterial. 2.2. Territorio y ciudad: nuevas formas de desarrollo urbano a través del agua. 3. Conclusión. 4. Bibliografía.

\begin{abstract}
Currently, more than fifty percent of the world's population lives in cities, configured as a meeting place for a modern multiculturalism, innovative and concerned with its environment, which does not accept to continue with the urban planning and growth of the last decades. This is how the current social movements emerge that call for a new urban and landscape planning where natural resources are taken into account, changing the classic paradigm of domination for another that is eco-sustainable. Consequently, through an eminently legal methodology, it is intended to expose the necessary relationship between landscape development and urban growth, through the immaterial value that water possesses in the creation of quality social environments. In view of the results, the scarce value of hydrological spaces as configurators of the environment and their null inclusion as elements of urban planning and quality of life in the city is evident.
\end{abstract}




\section{KEYWORDS}

paradigm shift, sustainability, city, human right.

\section{CONTENTS}

1. Introduction. 2. Water as the key to sustainable development. 2.1. Landscape and heritage: fluvial happiness as an immaterial heritage. 2.2. Territory and city: new of urban development through water. 3. Conclusion. 4. References.

\section{INTRODUCCIÓN}

La configuración de la Tierra ha sufrido miles de alteraciones a lo largo de décadas, no sólo en su composición químico-física, sino también cultural, espiritual, paisajística, estructural u orográfica, en parte gracias a la acción del agua sobre el territorio que, de forma constante, dibuja y perfila el contorno de nuestro entorno (Zaragoza-Martí, 2020). El agua, ya no sólo como recurso, ni como bien, sino como elemento de transformación y configuración de la vida, debe ocupar el lugar que le corresponde, olvidada por el constante transcurrir de la modernidad, la transnacionalización y la globalización en todos los niveles. Es necesario que el agua recupere el valor esencial que tuvo en los inicios de la civilización, pues como nos dice Espinosa (2011), pocas presencias son tan importantes y básicas como el agua, pero por ser algo tan obvio y cotidiano tiende a olvidarse por parte de aquellos que no la echan en falta e, incluso para éstos, es algo dado por supuesto, sin comprender a fondo sus innumerables implicaciones.

Desde sus orígenes el agua ha sido considerada como un recurso esencial para la Humanidad, elemento vehicular para el adecuado desarrollo de las sociedades, con valores emocionales, espirituales y de vida (Zaragoza-Martí, 2019a), que nos permite, como recuerda Abellán Contreras (2014), conocer y comprender el pasado y el futuro de las sociedades, puesto que supone, a la vez, fuente de vida, de prosperidad, de bienestar y de progreso para el desarrollo y el nacimiento de una civilización.

Desafortunadamente, la sociedad actual se encuentra sumida en un entorno de confusión prácticamente en todos los ámbitos, tanto a nivel estatal como social y de ciudadanía, lo que genera enormes desigualdades de magnitudes incalculables, especialmente en cuanto a la conceptualización, gestión, protección y promoción del agua, como derecho y como salvaguarda de la vida humana. Así lo entienden también Ortega Giménez y López Álvarez (2015), al manifestar que los principales desafíos en el ámbito hídrico sólo pueden entenderse en el amplio contexto de los sistemas socioeconómicos mundiales, cuyas causas más básicas radican en las desigualdades y en la disparidad en las relaciones de poder, agravadas por los retos sociales y medioambientales. Y ello puede poner en peligro la supervivencia del Planeta en cuanto a su desarrollo y crecimiento en una biosfera sostenible y saludable, dentro de la los seres vivos, en su conjunto, puedan desarrollar su vida con garantías, ya no sólo de mera subsistencia, sino de vivencia.

Ya en 2012, el World Water Council advirtió que 'las sociedades actuales se enfrentan a una crisis en el manejo del agua', que no es sino una crisis de gobernanza, pues la inactividad de los estados está generando no sólo consecuencias insostenibles para el medio dentro del que el agua forma parte, sino también crisis humanitarias como futuras fuentes de conflictos bélicos, políticos y jurídicos (Zaragoza-Martí, 2019b).

En consecuencia, se hace más necesario que nunca aprender a escuchar las advertencias que la propia naturaleza constantemente nos ofrece (bien sea mediante el deterioro exponencial de los recursos medioambientales, los huracanes, las migraciones atípicas de especies, la 
alteración en los ciclos de producción...), así como hacernos eco de las manifestaciones sociales más actuales, que promueven reestructurar el equilibrio del ecosistema con políticas menos agresivas con el entorno, apoyadas en una estructura jurídico-política universal que promueva el desarrollo sostenible y la igualdad en la promoción y protección de los derechos humanos, como base del desarrollo y entre los que se encuentra incluido el derecho al agua.

Para poder llevar a cabo esta tarea, de la que sin duda dependerá nuestra propia supervivencia, es necesario marcar un punto de inflexión, cambiar paradigmas, aunar fuerzas y crear un paraguas universal, cuyo fin último sea promover desarrollos sociales, urbanos, medioambientales y económicos sostenibles dentro del marco de los derechos fundamentales de las personas, con garantías de accesibilidad igualitaria y protección común. Y el agua aporta ese valor transversal, común, que exige una planificación y una gestión territorial e hidrológica más sostenible, un desarrollo urbano más ecológico e integral, una simbiosis entre el mundo urbano y el rural, recordando que las ciudades magnifican las relaciones del hombre con su entorno, con el territorio donde habita, con la sociedad y con el poder, dando forma a las relaciones político-estatales necesarias para salvaguardar los derechos de los ciudadanos. En suma, recobrar el carácter inmaterial del agua, como evocador de recuerdos, bienestar espiritual, salud física, coexistencia social sostenible y motor de cambio por una sociedad avanzada en derechos, en estructuras, en recursos y en entorno, tal y como reclama la Estrategia 2020 de la Unión Europea, basada sobre los pilares que promueve la Agenda 2030 de Naciones Unidas, con el objetivo general de crear un crecimiento inteligente, sostenible e integrador en todos sus ámbitos y recursos.

\section{EL AGUA COMO CLAVE DEL DESARROLLO SOSTENIBLE}

A lo largo de la historia, el agua ha sido vista como un recurso esencial para la vida (Sánchez, 2008), pues no en vano todas las manifestaciones ancestrales sobre la importancia del agua en la vida humana, evidencian la conciencia universal del valor supremo que tiene el agua como factor para el logro de las cotas más básicas de desarrollo material y espiritual del ser humano. Nos recuerda Espinosa (2011) que el agua es finita y no intercambiable, no se fabrica ni se destruye ni se sustituye por símbolos y, en cambio, sí es una pauta fundamental para entender y gobernar nuestra vida en sus variados registros, públicos y privados, hoy y mañana, primero para sobrevivir y, después, para realizarnos como personas.

Por ello, salvaguardar el agua y su valor como elemento inmaterial y transversal de la dignidad humana y como vehículo de cohesión y coexistencia simbiótica con el entorno natural y social es el objetivo al que debieran dirigirse todos los esfuerzos gubernativos: superar la visión mercantilista del agua y transitar hacia un paradigma ecosostenible de nueva gobernanza que genere oportunidades, oportunidades de desarrollo social, natural, ambiental, económico, cultural, espiritual o personal, oportunidades de cambiar la curva de destrucción a la que nos dirigimos, pues en términos sociales, como afirma Ávila (2002), la gestión del agua es y será la clave para la organización colectiva, pondrá a prueba la fuerza y la calidad de las instituciones y tendrá una influencia preponderante en la posibilidad de desarrollo de los pueblos.

Incluso la jurisprudencia nos muestra la necesidad de imponer un cambio en la interpretación y significado de los recursos a nuestro alcance y de reubicar cada elemento vital en su correspondiente lugar, realzando la importancia de interpretar el derecho al agua a la luz de las condiciones de vida actuales, ya que su configuración responde a la interacción recíproca y continua de diversos instrumentos internacionales de derechos humanos, así como a la 
integración y cada vez mayor coordinación e interdependencia política entre Estados en torno a la protección de derechos y garantías que repercuten en beneficio de los bienes que subyacen a la democracia y al estado de derecho (Tribunal Europeo de Derechos Humanos, caso Henaf vs Francia-Sentencia de 2003, párrafo 55). Nos encontramos en un mundo altamente tecnificado y globalizado y global debe ser, por tanto, también su respuesta ante las nuevas crisis, no sólo ya económicas, que la Humanidad está viviendo.

\subsection{PAISAJE Y PATRIMONIO: LA FLUVIOFELICIDAD COMO PATRIMONIO INMATERIAL}

La percepción humana sobre el entorno y los recursos que el mismo dispone evoluciona en función de las connotaciones económicas, sociales, jurídicas, culturales, ambientales y tecnológicas de cada momento, por lo que podemos afirmar, en comunión con Langford \& Khalfan (2006), que los conflictos que se suscitan en relación con el agua no son nuevos, sino que lo novedoso es la escala que el problema ha alcanzado en la actualidad, herederos del paradigma hídrico tradicional e incrementados por la alarmante crisis ambiental y el crecimiento urbanístico descontrolado. Miguel de Unamuno decía que los ríos son el alma del paisaje, por lo que urge hacer la paz con nuestros ríos e instaurar un nuevo orden ético en la gestión de las aguas (Arrojo Agudo, 2015).

Esta vuelta a la ética jurídico-hidrológica es lo que reclaman los movimientos sociales contemporáneos, sobre la consideración de los recursos hídricos como patrimonio de la biosfera, la cual resalta los 'otros' valores no patrimoniales del agua y los interrelaciona con los elementos básicos de todos los derechos humanos (Zaragoza-Martí, 2018). Es esa visión ecosistemática sobre la que, por ejemplo, la Nueva Cultura del Agua reclama un cambio de mentalidad en la percepción del agua, una percepción del agua más holística, que recupere la memoria del agua y realce la dialéctica entre el ser humano y el agua (Martínez Gil, 2004), teniendo en cuenta, también, que los caminos por donde discurre el agua y la vida no son sólo meros ríos o corredores ecológicos encargados de garantizar el equilibrio, sino que también transmiten recuerdos, vivencias, emociones y felicidad, uniendo humanidad y naturaleza como enclave sobre el que crece y se desarrolla el conjunto de la vida.

Sin duda, uno de los elementos esenciales de esa eco-revolución es el paisaje, cuya importancia radica en ser el factor de calidad de vida de todas las personas, como elemento de identidad cultural, ya que cada sociedad o pueblo tiene en su territorio uno de los componentes fundamentales de su proyecto colectivo y expresa en él su cultura, convirtiéndolo así en paisaje (Centro de Estudios del Paisaje y Territorio, 2012). Lo mismo nos dice Checa-Artasu (2018) al afirmar que el paisaje contiene valores tangibles e intangibles asociados a las relaciones sociales y políticas construidas a lo largo del tiempo y desarrolladas por una comunidad o sociedad. Y es que el paisaje no es sólo geografía, técnica histórica o delimitación territorial, como destaca el Convenio Europeo del Paisaje, sino que es mucho más, es la manta que nos envuelve, es cultura, es memoria, es ecología, es respeto, es tradición, es historia... y forma indisoluble del desarrollo humano.

El paisaje es tanto la fisonomía de un territorio, con todos sus elementos naturales y antropogénicos, como también los sentimientos y las emociones que despierta en el momento de contemplarlo, pues como reclama Navarro Bello (2004), el paisaje no es sólo una marca en un territorio, sino también un vestigio dejado en la memoria individual y colectiva. Dentro de este imaginario común que nos ofrece el paisaje de nuestro entorno, en el que nos deleitamos cuando miramos al horizonte buscando respuestas, un momento de calma, la reflexión del día o simplemente la belleza del mundo, el agua representa un papel protagonista, ya que configura 
el paisaje y su tipología, es un elemento de planificación y ordenación territorial que exige respetar el curso natural, pues, según Gabardón de la Banda (2014) es un vector de diversos factores como recurso de los sistemas bióticos y sociales. De esta forma, entran en comunión paisaje y agua configurando lo que denominamos paisaje fluvial, elemento inmaterial de la evolución y desarrollo de los pueblos, pues en cierta manera, nos dice Ribas Palom (2006), de la calidad del paisaje depende la calidad de vida de las personas que en el mismo habitan.

Durante años, junto al acto de olvido que condujo a no regular adecuadamente el agua como elemento vehicular del derecho a la vida, el paisaje fluvial también ha sufrido una percepción negativa (Durán Vian, 2018) basada en una errónea visión del río, columna vertebral del mismo, que ha producido una inexistencia de la función social y medioambiental de este entorno, pues sólo se resaltaba su valor estratégico, económico o energético, dejando de lado el valor inmaterial del mismo como creador de espiritualidad cultural y vivencia social. Muchos ríos, ramblas, humedales, lagos, estanques, lagunas... recorren entornos urbanos en los que aún hoy se conciben como recursos y elementos independientes, asilados y separados del conjunto ambiental y paisajístico al que pertenecen, perdiendo su propia identidad y valor. Además, su planificación y gestión no siempre es adecuada, dando lugar a espacios poco apacibles, deshabitados y, en definitiva, marginados (Fernández Pablos, 2015).

Afortunadamente, dentro de la reivindicativa oleada social entorno a los elementos medioambientales y su reequilibrio natural, los organismos supranacionales, como es el caso de la Comisión Europea (2014), apuestan paulatinamente, por recobrar el valor y el simbolismo que antaño tuvieron los paisajes del agua, desarrollando 'la infraestructura verde' que favorece la conservación y la restauración funcional entre el medio fluvial y el urbano, creando nuevos espacios de confluencia, favoreciendo la biodiversidad, la regulación microclimática y del ciclo del agua, depurando la contaminación atmosférica y el ruido. Es decir, se produce un cambio de paradigma, ya no sólo en la consideración del agua como elemento inmaterial, sino también en la importancia que la misma tiene en la configuración del paisaje, dotando a éste, a su vez, de la importancia necesaria como elemento vertebrador en la construcción de las nuevas ciudades verdes, con entornos planificados no para explotar los recursos desgastando su entorno, sino resaltando la importancia de los mismos como centros neurálgicos de la actividad social y cultural, cambiando el coste económico por un valor inmaterial como patrimonio, dador de bienestar social, cultural y personal, en simbiosis con el pasado histórico en el que el agua era fuente de vida. El agua, el paisaje, el entorno, la cultura paisajística e hidrográfica, los recursos, los bienes y los valores aquí nombrados tienen, como dicen Bolund \& Hunhammar (1999), funciones sociales, recreativas, de ocio, deportivas, educativas, terapéuticas, estéticas, turísticas e incluso laborales, pues todo ello contribuye a potenciar la calidad de la vida (Macdonald, 2007), debiendo protegerse y fomentarse, pues sólo mediante los pilares de la corresponsabilidad compartida se podrá crear, por y para todos, un entorno de vida adecuada, de calidad, accesible y en consonancia y respeto con el entorno que lo configura.

En consecuencia, mientras no surjan nuevos valores que rijan nuestras conductas, no habrá un nuevo orden y no se podrá instaurar una ética hidrológica basada en una concepción de los ríos y del agua que supere la simple idea de un recurso, desde la perspectiva de la nueva cultura del agua, que entienda no sólo las funciones naturales de los ríos, sino también su vinculación emocional con los seres humanos (Martínez Gil, 2010). Por tanto, es necesario recuperar esa memoria hidrofluvial que dota de permanencia a las relaciones entre la sociedad y el agua, el paisaje y el agua, la naturaleza y el agua, construyendo una nueva actitud ecosocial hacia los paisajes del agua como patrimonio común, puesto que el paisaje, en general, y los paisajes fluviales, en particular, no son ajenos a la realidad social cotidiana, alcanzado de esta manera 
la denominada fluviofelicidad, ese placer intenso que se produce al entrar en contacto con el medio fluvial. Pues los bienes ambientales, incluidos los hídricos, no pueden sólo ya concebirse como simples medios o herramientas de producción económica, sino que deben verse como instrumentos que mejoran la vida de las personas, física, espiritual y socialmente.

\subsection{TERRITORIO Y CIUDAD: NUEVAS FORMAS DE DESARROLLO URBANO A TRAVÉS DEL AGUA}

El skyline de un asentamiento humano, su contorno, su paisaje observado desde la lejanía nos habla, nos atrae a acercarnos y a observar, para recibir sensaciones y emociones que perfilan el conocimiento y el disfrute sobre ese territorio, marcado por las huellas del pasado que nos muestran la historia que ha vivido. Una historia que puede extraerse del agua, pues ésta tiene memoria como evocadora de espiritualidad y dibujante de la realidad sobre la que perfila su propia extinción ante el crecimiento de las urbes. No en vano, son numerosos los casos en los que el paisaje (incluido el fluvial), han perdido su identidad como consecuencia del desarrollo urbanístico y de la falta de sensibilización y respeto hacia él (Cuello Guijón, 2009).

En sus orígenes, la ciudad fue concebida como un lugar de reunión, de fraternidad, de relación, pero evolucionó hacia una institución, nos dice Alvarado Alegría (2016), convertida en objeto humano producto de la urbanización que, dependiendo de cómo era construida, planeada y gestionada, es o puede ser un elemento de vital importancia para garantizar los derechos humanos o, por el contrario, vulnerarlos.

Desde las primeras ciudades hasta nuestros días, el crecimiento poblacional ha sido progresivo, pero al relacionarlo con la delimitación geográfica toma relevancia el concepto de sustentabilidad (Padrón Cruz, 2009), ya que la revolución urbanística moderna y el crecimiento poblacional asimétrico han quebrado el equilibrio natural de las urbes, no sólo en cuanto a la configuración de la ciudad como continente humano, sino también como contenido social y cultural que favorece el desarrollo en comunidad. En consecuencia, las civilizaciones urbanas impiden al hombre percatarse de sus raíces ecológico-económicas provenientes de sus actividades productivas, de intercambio de bienes y servicios, generando un deterioro en el entorno y dando todo el sustento únicamente al sistema económico como proveedor de bienestar (Correa, 2006). Desaparece el nexo de unión con el entono y con el valor de la ciudad como proveedor de salud y bienestar físico y social, pues como decía Harvey (2008) la calidad de la vida urbana se ha convertido en una mercancía, como la ciudad misma, en un mundo en el que el consumismo, el turismo, las industrias culturales y las basadas en el conocimiento se han convertido en aspectos esenciales de la economía política urbana. Especialmente, cuando la ciudad ha dejado de ser construida en comunidad para ser alzada según los intereses de una reducida élite que perpetua valores individuales y privados ajenos al valor social que tiene crear y participar en la ciudad, también como derecho de las personas y de los ciudadanos, por erigir la forma de vida a seguir, en fraternidad con el medio que los envuelve.

Ello exige la necesidad de un cambio dentro de la estructura de la economía tradicional, la cual se ha mostrado incapaz de asumir e integrar los valores ambientales y los intereses de desarrollo actual. Hay que pasar de un paradigma de la dominación de la naturaleza hacia otro que asigne un enfoque científico-técnico más sabio, humilde y paciente, que reconozca los ciclos y las funciones que tienen los equilibrios dinámicos de la biosfera, con el fin de aunar el desarrollo humano con el orden natural (Zaragoza-Martí, 2018). En concordancia con ello, nos dice la OCDE, las respuestas a esa nueva gobernanza deben adaptarse a las especificidades territoriales, puesto que no hay una solución única ante los actuales conflictos por los recursos 
y se debe reconocer el nexo de unión entre las políticas de gobernanza y el contexto geográfico en el que se aplican, promoviendo la participación democrática de la ciudadanía sobre el respeto de los derechos humanos, con base en los principios de equidad, solidaridad y sostenibilidad.

Hoy en día, más del cincuenta por ciento de la población mundial vive en las urbes, configuradas éstas como lugar de reunión de una multiculturalidad moderna, innovadora y comprometida con su entorno, que afortunadamente ya no acepta seguir con el planeamiento urbanístico y de crecimiento desmesurado desarrollado durante las últimas décadas. Surgen así, continuando con las reivindicaciones en el ámbito de los derechos y del reconocimiento del agua como derecho fundamental, los movimientos sociales entorno a la ciudad y a la necesidad de recobrar la misma como espacio público en el que el ciudadano y la persona pueden encontrarse y construir comúnmente una ciudad que promueva y proteja los derechos fundamentales necesarios para el desarrollo de una vida adecuada, sobre la solidaridad y la participación de todos. La Declaración de Derechos Humanos Emergentes ya reflejaba la necesidad de disponer del espacio ciudad como elemento esencial para el desarrollo y la mejora de la calidad de vida, un espacio urbano que facilite la cohesión sociocultural de las comunidades, puesto que comprendida la ciudad como un todo orgánico, como dice la Carta Europea hacia la sostenibilidad, ésta permite desarrollar y proteger muchos otros derechos fundamentales. Es el hilo de la historia de nuestra vida, una vida que debe despojarse del afán capitalista para retornar a la paz natural que aporta vivir en consonancia y equilibrio con las necesidades humanas y las naturales. De igual manera lo afirma Jiménez Pacheco [29] cuando reclama la necesidad de un espacio radical de vocación transformadora y carácter inalienable que se traduzca a la vida cotidiana, donde una persona común logre su individualidad en una identidad colectiva.

Es ya sumamente necesario conseguir el reclamado cambio de paradigma, concepción, gestión o gobernanza humana, a nivel global, pues de nada sirve abogar por cambios aislados en sociedades desarrolladas sino se salvaguarda también la vida y la naturaleza en el resto de sociedades, entornos, comunidades o asentamientos diversos, ya que el acceso al agua, el bienestar natural, la paz espiritual, el desarrollo sociocultural.... son elementos igualmente necesarios para todas las sociedades, desarrolladas, en vías de desarrollo o excluidas de los sistemas estatales. No conseguiremos ningún resultado si tenemos ciudades verdes en el primer mundo y sobreexplotación natural en el mundo subdesarrollado. Ha llegado ya el momento de evolucionar hacia un desarrollo sostenible en el tiempo, donde los recursos se utilicen y se recuperen sin costes para la vida o para el medio natural, pues sin agua no hay vida (ZaragozaMartí, 209b). Pero tampoco hay crecimiento económico o social, no hay recreación ambiental, no hay arquitectura paisajística, no hay ciudades-derecho, no hay, en suma, alma en el Planeta.

El elemento común a todo ello es, justamente, el recurso hídrico, el agua, ese líquido trasparente reflejo de la historia evolutiva del Planeta: el agua es, forzosamente, un bien de la Humanidad y ella misma es la herramienta que debemos utilizar para garantizar la supervivencia del Planeta y el desarrollo de la vida sobre el mismo, bajo parámetros sostenibles, de crecimiento controlado en sintonía con el aumento y la recuperación de la biosfera, pues cualquier estrategia de sustentabilidad debe ser capaz de crear cultura de responsabilidad, como apunta en II Informe de Naciones Unidas sobre los Recursos Hídricos, acompañada de información y de incentivos para cuidar el medio ambiente.

Si somos capaces de concebir un asentamiento humano entorno al paisaje que el agua perfila sobre el territorio, protegiendo dicho recurso como fuente de vida, alcanzamos un desarrollo social como conjunto, lo que originará un espacio de unión, de comunión, de cooperación, donde contenido y continente sean uno, donde personas y recursos se retroalimenten y alcancen 
un estadio de vida superior, venciendo el aislamiento actualmente ofrecido en las ciudades, donde caminamos entre millones de personas, pero sin ser una de ellas, donde viajamos kilómetros hacia otros lugares de mayor belleza y bienestar, pero sin apreciar la esencia que ello mismo ofrece. ¿Por qué viajamos? Porque buscamos aquello que no tenemos, un paisaje, una sensación, una emoción, un recuerdo... eso que sólo conseguimos a través de la historia y esa historia nos la transmite el agua cuando refleja su memoria en nuestro entorno.

\section{CONCLUSIÓN}

El mundo se encuentra desarmado, frustrado, caóticamente gestionado, desigual en recursos, desarrollos y economías, degradado ambientalmente y fragmentado política y socialmente. Parece un futuro sin esperanzas y pocas hay como no haya una respuesta colectiva a gran escala, que tome como vehículo resolutivo los elementos más básicos del desarrollo humano y natural, creando un medio en el que se pueda habitar en comunidad y comunión con la esencia misma del Planeta. El hombre no es hombre sin aquellas características que lo definen como tal, es decir, sin sus derechos fundamentales, sin poder ejercerlos en igualdad de condiciones, sin sesgos y con independencia del lugar en que se halle.

Y no hay derecho más básico y fundamental que el que nos ofrece el agua, en su acceso y en su gestión y promoción también como recurso, recurso natural, que no imput económico, capaz de dar forma a una ciudad, salvaguardar la calidad de vida de las personas y promover el desarrollo del resto de los derechos del hombre. Pero para ello hay que conjugar una acción conjunta de los diversos organismos que planifique una respuesta homogénea en todos los territorios del planeta, en aras a recobrar la memoria de aquel momento en que la Humanidad coexistía con su entorno y con los recursos que el mismo le ofrecía, como salvoconducto para el nuevo ecodesarrollo sostenible, perdurable, planificado y bien gestionado.

Durante décadas se ha reclamado mayor cobertura para un elemento tan transversal como el agua, cuyo olvido original ha ocasionado ese quebrantamiento del equilibrio natural, que muchos llaman dumping ambiental, pero cuyo valor esencial radica en ser la fuente a partir de la que debe reescribirse la historia y la arquitectura de la Humanidad. Es un elemento, un valor, un recurso esencial para dar vitalidad y viabilidad a los nuevos planes de 'Sostenibilidad Justa' o justicia ambiental, que conecta con la persona, con la sociedad y con el entorno, configurando el telón paisajístico de nuestra propia biografía. Urge reconocer el peso del agua, en su forma básica o artística a través de los ríos de la vida, pues ello es patrimonio cultural inmaterial, cuyas vivencias, experiencias, aprendizajes, sensaciones, emociones y recuerdos se trasmiten de generación en generación por las comunidades y grupos, en función de la interacción con la naturaleza y su historia, infundiéndoles un sentimiento de identidad y continuidad, contribuyendo a promover también el respeto por la diversidad cultural, la creatividad humana y la salvaguarda de nuestro entorno natural y personal. Es el momento de actuar, de exigir cambios, generar regulaciones que protejan el agua y los elementos que en ella se recogen, pues no podemos permanecer inmunes ante la inactividad de las instituciones, el desalojo climático o la desaparición de nuestra especie. Es necesario poder formar parte de nuestra propia ciudad, de crearla, moldearla y reformarla según las necesidades de quienes la habitan y recordar porqué el simple sonido de un riachuelo altera nuestros sentidos, nos transporta a un mundo verde, nos evoca vivencias ancestrales, en suma, nos reconforta.

Como decía Marx, la acción es conocimiento y, por tanto, en nuestras manos está el realizar las acciones oportunas para contribuir a un correcto desarrollo humano que nos permita gozar de los recursos que el Planeta Tierra nos ofrece, en condiciones de igualdad y universalidad, 
recobrando esa memoria sobre nuestro propio desarrollo, vislumbrada gota a gota en los reflejos del pasado que el agua aflora en las piedras de nuestro camino.

\section{BIBLIOGRAFÍA}

Abellán Contreras, F.J. (2014), El aprovechamiento de las aguas en la Ley de 13 de junio de 1879.

Trayectoria de un texto legislativo a la luz de la optimización y eficacia de los recursos hídricos. En Sanchis-Ibor, C., Palau-Salvador, G., Mangue Alférez, I. \& Martínez-Sanmartín, L.P. (Eds.). Irrigation, Society, Landscape, Tribute to Thomas F. Click (pp. 686-698), Valencia: Universidad Politécnica de Valencia. Recuperado de https://doi.org/10.4995/ISL2014.2014.148

Alvarado Alegría, N. (2016), El derecho a la ciudad como derecho social en el estado constitucional. Trabajo presentado en el I Congreso de Filosofía del derecho para el mundo latino, España: Alicante.

Arrojo Agudo, P. (2015), Punto de partida: el reto de integrar valores y principios ecológicos, éticos y sociales. En Del Moral Ituarte, L., Arrojo Agudo, P. \& Herrera Grao, T. (Coords.). El agua: perspectiva ecosistemática y gestión integrada (pp. 8-15), Zaragoza: Fundación Nueva Cultura del Agua.

Ávila, P. (2002), Agua, medio ambiente y desarrollo en el s. XXI, México: Suma.

Bolund, P., \& Hunhammar, S. (1999), Ecosystem services in urban areas, Ecological Economics, 29, 203-201. Recuperado de https://doi.org/10.1016/S0921-8009(99)00013-0

Centro de Estudios Paisaje y Territorio. (2012), Los paisajes fluviales en la planificación y gestión del agua: elementos para la consideración del paisaje en la Cuenca Hidrográfica del Guadalquivir. España: Universidad de Sevilla y Ministerio de Agricultura, Alimentación y Medio Ambiente.

Chesa-Artasu, M.M. (2018), El paisaje como bien común y como un derecho. Algunas reflexiones, Revista Bibliográfica de Geografía y Ciencias Sociales, XXII(1), 1-18.

Comisión Europea. (2014), Construir una infraestructura verde para Europa, Luxemburgo: Oficina de Publicación Oficiales de la Unión Europea.

Correa, G., \& Rozas, P. (2006), Desarrollo urbano e inversiones en infraestructura: elementos para la toma de decisiones, Santiago de Chile: Naciones Unidas CEPAL.

Cuello Guijón, A. (2009), Los tramos fluviales urbanos como ámbitos de aprendizaje. Una valoración de su potencial educativo y los obstáculos que plantea su utilización. En Junyent i Pubill, M. \& Cano Muñoz, L. (Coords.). Investigar para avanzar en educación ambiental (pp. 53-84), España: Ministerio de Medio Ambienta, Rural y Marino.

Durán Vian, F., Serrano-Martínez, M., \& Pons Izquierdo, J. J. (2018), Recuperación del paisaje fluvial y su revalorización social: el caso de Arévalo (Ávila). Boletín de la Asociación de Geógrafos Españoles, 78, 419-443. Recuperado de https://doi.org/10.21138/bage.2719

Espinosa, L. (2011), Reflexiones sobre el agua: un espejo de nuestro tiempo. Dilemata, 2(6), 81-99.

Fernández Pablos, E.M., \& Yáñez Conde, E. (2015), El valor de las áreas periurbanas como espacios multifuncionales en el sureste de Madrid. Revista de Ciencia, Tecnología y Medio Ambiente, XIII, $1-24$.

Gabardón de la Banda, J.F. (2014), La Ciudad y el Río como paisaje geohistórico y su proyección en el ámbito educativo. Escuela Abierta, 17, 211-240.

Harvey, D. (2008), El derecho a la ciudad. Net left Review, 53(4), 23-29.

Jiménez Pacheco, P. (2016), Claves epistemológicas para descifrar el derecho a la ciudad de Henri Lefebvre. Estoa, 8(5), 21-28. Recuperado de https://doi.org/10.18537/est.v005.n008.03

Langford, M. \& Khalfan, A. (2006), Introducción al agua como derecho humano. En VV.AA., La gota de la vida: hacia una visión sustentable y democrática del agua (pp. 30-62), Cuba: Böll.

Macdonald, E. (2007), Urban Waterfront promenades and physical activity by older adults: the case of Vancouver. Journal of Architectural and Planning research, 24(3), 181-198.

Martínez Gil, F.J. (2004), La Nueva Cultura al Agua. En Arrojo Agudo, P. (Coord.). El agua en España: propuestas de futuro (pp. 287-326), Madrid: Ediciones del Oriente y del Mediterráneo.

Martínez Gil, J. (2010), Una nueva cultura del agua y de la vida. La experiencia fluviofeliz, Zaragoza: 
Fundación Nueva Cultura del Agua.

Navarro Bello, G. (2004), Una aproximación al paisaje como patrimonio cultural, identidad y constructo mental de una sociedad. Apuntes para la búsqueda de invariantes que determinen la patrimonialidad de un paisaje. Revista Electrónica DU \& Revista de Diseño Urbano y Paisaje, 1(1), $1-15$.

Ortega Giménez, A. \& López Álvarez, A. (2015), El derecho humano al agua: fundamentación jurídica, reconocimiento y contenido. En Benito López, M.A. (Dir.). Agua y Derecho, retos para el s. XXI (pp. 36-50), Navarra: Aranzadi: Navarra.

Padrón Cruz, A.C., \& Cantú Martínez, P.C. (2009), El recurso agua en el entorno de las ciudades sustentables, CULCyT, 6(31), 15-25.

Ribas Palom, A. (2006), Los paisajes del agua como paisajes culturales. Conceptos, métodos y experiencias prácticas para su interpretación y valorización. VII Coloquio sobre Planificación y gestión del Agua. Faro.

Sánchez, V.M. (2008), Hacia un derecho humano fundamental al agua en el derecho internacional. Revista Electrónica de Estudios Internacionales, 16, 1-23.

Zaragoza-Martí, M.F. (2018). El derecho humano al agua: un recorrido por la Constitución Española y sus homólogas. En Vega Baeza, M.R., De la Fuente Anunciba, R., \& Romero Sánchez, G.

(Coords.). Focalizando áreas del saber desde sus nuevas culturas (pp. 483-497), Barcelona: Gedisa: Barcelona.

Zaragoza-Martí, M.F. (2019a), El Bajo Segura como enclave geoestratégico del sureste español: recorrido normativo del derecho al agua como elemento configurador del paisaje históricopatrimonial. En Álvarez-Vázquez, M.A. \& De Uña-Álvarez, E. (Coords.). Investigación, gestión y valores del agua en el mundo actual (pp. 133-140), Madrid: Dykinson. Recuperado de https://doi.org/10.2307/j.ctv102bkpf.13

Zaragoza-Marti, M.F. (2019b) La exigibilidad de un cambio de paradigma ecosocial como herramienta de planificación y gestión hidrológica. En Melgarejo Moreno, J. (Ed.). Congreso Nacional del Agua 2019: innovación y sostenibilidad (pp. 791-800), España: Universidad de Alicante: Alicante.

Zaragoza-Martí, M.F. (2020), El derecho al paisaje fluvial como elemento de planificación territorial. En Rivera Mateos, M. (Coord.). Usos sostenibles de la Tierra y desarrollo humano (pp. 154-168), Sevilla: Egregius.

\section{Breve currículo:}

\section{María Francisca Zaragoza Martí}

Profesora de derecho constitucional de la Facultad de Derecho de la Universidad de Alicante (España). Doctora en Derecho Mención Internacional por la Universidad Miguel Hernández de Elche (UMHEspaña). Licenciada también en Ciencias Políticas y de la Administración (CCPP). Master en Diplomacia y Relaciones Internacionales y en Acceso a la Procura. Ha trabajado en la Secretaría de Estado para la Unión Europea y en la Ofician Europe Direct (España). Ha impartido clases de derecho constitucional e instituciones básicas de derecho público en la UMH en la Licenciatura de Derecho y en CCPP y en la Diplomatura de Relaciones Laborales, así como en los prácticums de Derecho. Miembro del Instituto de Geografía y del Instituto del Agua y de las Ciencias Ambientales, de la Universidad de Alicante. 